\title{
Study Subject Participation Status
}

National Cancer Institute

\section{Source}

National Cancer Institute. Study Subject Participation Status. NCI Thesaurus. Code C70732.

The status of a subject in relationship to his participation in a given clinical study, at a particular time and date. 